\title{
Engagement in higher education. Who's not engaging?
}

James Wilkinson

Queen Mary University, London, UK

\section{Abstract}

Just as undergraduates need to develop critical capacities, so as to scrutinise and justify beliefs, decisions and actions (Barnett, 1997), higher education teachers need to consider critically their own assumptions about and orientations towards teaching (Gow and Kember, 1993). These are often unexamined and unchallenged, so teachers can remain unaware of implications for students' learning (Mezirow, 1990; Larrivee, 2000). Regarding subject disciplinary literacy development, relevant assumptions concern several important challenges: the complexity and opaqueness of disciplinary reading and writing practices (Lea and Street, 1998; Meyer and Land, 2003; Haggis, 2003; Gourlay, 2009); issues concerning engagement and assumed student deficits (Mann, 2001; Haggis, 2003; 2006); and the potentially alienating environment, norms, values and practices of higher education (Mann, 2001; Haggis, 2006; Bryson and Hand, 2007).

This paper discusses these challenges and reports on a small-scale study investigating the context of students' reading and writing difficulties at a London-based, Russell Group university. Methods included analysis of data from interviews with academics and student discussion groups, and from teaching observations. The findings suggest that the teaching orientations of learning facilitation and knowledge transmission, and their links to different learning approaches and outcomes, continue to shape many undergraduates' experience, for better or worse.

The paper contributes to understanding these links using Self-Determination Theory (Ryan and Deci, 2000). Accordingly, teaching oriented towards learning facilitation, but not knowledge transmission, fosters students' feelings of competence, autonomy and relatedness, assisting internalisation of externally regulated behaviours, and increasing preparedness for engaged, self-directed learning (Niemiec and Ryan, 2009). 
Keywords: academic reading and writing; teaching conceptions and orientations; threshold concepts and practices; engagement; alienation; Self-Determination Theory; motivation.

\section{Introduction}

Teaching on undergraduate degree programmes should reveal to students their subject discipline's ways of knowing the world and solving its problems. An outcome of this teaching is not just knowledge. A greater challenge is to build students' capacities for inquiry, reading and writing in the discipline, which allow them to discover, unpack and apply knowledge critically in new contexts, for new purposes (Barnett, 1997; Lea and Street, 1998; Haggis, 2003; Wingate, 2015). It is challenging because these practices, their underpinning epistemological foundations and the sociocultural conditions in which students have to learn them, are likely to be alien for students (Mann, 2001, Haggis, 2006; Bryson and Hand, 2007). Teaching should therefore also create familiarity and cohesion (Rathje, 2007) and satisfy students' psychological needs so that they are motivated to engage meaningfully in self-directed learning (Niemiec and Ryan, 2009).

In this paper I argue that while a lot of higher education teaching is concerned with revealing knowledge, not enough is done to build the competences and motivation needed by students to reveal that knowledge for themselves, and for engaging with their subject discipline's reading and writing practices. The paper also highlights the need for higher education teachers to reflect critically on their teaching assumptions and practice, and to be supported in this.

Evidence for this argument comes from three sources: from my own experience of teaching in higher education, which includes 20 years in a former polytechnic and, currently, in educational development at a London-based, Russell Group university and in learning development at a similar institution; from literature perspectives; and from a smallscale study at the university where I work as a learning developer.

A central element in the argument concerns two conceptions of what it means to teach, related teaching orientations towards either learning facilitation or knowledge transmission, 
and links to more or less desirable learning approaches and outcomes, as identified by Gow and Kember (1993).

I used to think that telling students things meant that I was teaching. However, in their work I often found that they had not understood important concepts, nor could they apply practices I had told them about. And yet in my lectures and slides, online materials, assessment instructions and criteria, I had spelled it out for them. I tended to agree with colleagues who said it was due to widening participation, the massification of higher education and related deficits, not least students' lack of engagement with literature and practices needed for their work. That telling students things, doing little more than transmit knowledge was itself a deficit, and that I also was not engaging adequately with literature and practices needed for my work, did not occur to me. Critical reflection facilitated important changes in my practice towards more learner-centred, active and interactive learning (Doyle, 2008; Weimer, 2013), as well as enquiry based learning (Allan and Powell, 2007), and these were accompanied by substantial improvements in my students' engagement, enthusiasm and results, as well as my own enjoyment in teaching (Wilkinson and Olason, 2012).

Assuming that teaching means transmitting knowledge was one of the teaching conceptions identified by Gow and Kember. The other one was that teaching is understood to mean bringing about intended learning. The small-scale study reported in this article suggests that these two conceptions of teaching and related orientations towards either 'learning facilitation' or 'knowledge transmission' continue to shape undergraduates' experience, for better or worse. Experience observing more than 300 teaching sessions in my current jobs convinces me that these teaching orientations remain salient and are widespread in current higher education teaching.

The study was initiated after nine students from a Humanities and Social Sciences (HSS) department had been referred to learning development and attended a workshop, which I co-facilitated in March 2017, because plagiarised material had been found in their coursework. Positive feedback led to conversations with academics in the department, who reported widespread difficulties with first year undergraduates' reading and writing, and problems with motivation, engagement and self-directed learning. This collaborative, exploratory study aimed to help the department understand better the context of these difficulties, to suggest possible responses and to identify implications for further research. 
This paper first discusses literature on challenges relating to students' disciplinary reading and writing, engagement and alienation, and suggested responses. The challenges are interpreted through three perspectives: Gow and Kember's (1993) 'learning facilitation' and 'knowledge facilitation' teaching orientations; Self-Determination Theory (SDT), which suggests that satisfying, or failing to satisfy, students' psychological need for feelings of competence, autonomy and relatedness is likely to affect their motivation and agency in self-directed learning (Ryan and Deci, 2000; Niemiec and Ryan, 2009); and theory on cohesion and the need to facilitate familiarity in environments characterised by cultural diversity (Rathje, 2007).

Next, methods used and their limitations are described, after which findings are presented and discussed. This is followed by suggested responses, including teaching methods, which higher education teachers can use to assist development of students' disciplinary reading and writing. Experience of combining two of these is also described. The paper finishes with tentative conclusions and implications for further research. Three appendices provide further details on teaching methods, and a fourth reports on the experience of combining approaches, and details of how a refined adaptation of this can be used for staff development.

\section{Literature}

\subsection{Challenges for students' reading and writing}

In their subject disciplinary reading and writing, undergraduates have to grapple with what have been referred to as 'Threshold Concepts' (Meyer and Land, 2003; 2005) and 'Threshold Practices' (Gourlay, 2009), which are inherently troublesome in nature. These are fundamental to learning in disciplinary areas because how they are taught and how students get to grips with them can either block or open up further learning in their field. Grasping threshold concepts is also transformational, revealing to students how phenomena are perceived and understood within their discipline, and allowing them to discover new ways of viewing 'subject matter, subject landscape, or even world view' (Meyer and Land, 2005, p.373).

A crucial threshold practice is being critical, which students must grasp if they are to develop higher education's goal of developing criticality (Barnett, 1997). For students, this requires engagement with literature, openness to different perspectives and awareness 
that texts do not provide incontrovertible truths but arguments which can be contested (Abbott 2013, cited Wingate, 2015).

Further challenges arise from academics often having tacit rather than explicit knowledge of their own literacy practices (Lea and Street, 1998) and from assumptions that students already know how to read for academic purposes, are able and confident to be strategic in what and how much to read, and can interpret correctly the hidden requirements of assessment essay questions (Haggis, 2006). This means that academic reading and writing are often not explicitly taught in the classroom, so that students' experiences of these practices remain 'indeterminate and opaque' (Gourlay, 2009, p.181).

Often students only become aware of these threshold practices when they receive negative assessment feedback (Haggis, 2006). These practices are made explicit in coursework rubrics and assessment criteria, but having only limited or no understanding of their subject discipline's epistemological orientations, these instructions are often poorly understood (Lea and Street, 1998). Moreover, over-reliance by teachers on knowledge transmission can encourage students to assume they should memorise and learn transmitted content by rote, regurgitating it in their work, rather than processing it so that they can make abstractions and apply these meaningfully in new contexts, for new purposes (Haggis, 2006). Not learning to approach their studies in this way also makes it less likely that students will integrate new material meaningfully with their existing knowledge, a serious problem from a constructivist perspective (Ausubel, 1963).

Without explicit, contextualised literacy teaching, developing competence in academic reading and writing is difficult. SDT predicts that if students do not feel competent, this will reduce their self-motivation and willingness '...to learn; extend themselves; master new skills; and apply their talents responsibly'(Ryan and Deci, 2000, p.68).

\subsection{Engagement and alienation}

Discourse on student engagement has often featured learning approaches, notably 'deep' and 'surface', identified by Marton and Säljö (1976), and 'strategic' (Ramsden, 1992; Prosser and Trigwell, 1999; Biggs and Tang, 2011). 
Briefly, 'surface-level processing' typically involves a 'reproductive' approach, learning by rote the text, or 'sign' (e.g. words and numbers), whereas with 'deep-level processing', the student aims to understand 'what is signified' (Marton and Säljö, 1976:7), and engage in more meaningful and higher level learning. Understood in this way, surface approaches can be linked to poor paraphrasing skills and to plagiarism. The 'strategic' approach is similar to surface learning but entails more active involvement in specific, extrinsically motivated activity, such as exam preparation (Ramsden, 1992; Prosser and Trigwell, 1999). Gow and Kember (1993) found relationships between learning facilitation orientations and meaningful, deep learning, and between transmission-based teaching and surface approaches.

However, the emphasis on these approaches, and the generalisations and applications that have been inferred from Marton and Säljö's (1976) phenomenographic research, have been questioned. Empirical evidence suggests that in different circumstances, students can adopt all three of the above approaches (Mann, 2001). It is more helpful to view engagement as a continuum on which the same individuals can act at different levels (Bryson and Hand, 2007). Moreover, 'understanding' in higher education - the supposed outcome of deep learning - is far from straightforward but requires application of complex skills and practices (Prosser and Trigwell 1999, cited Haggis, 2003), which are not only cognitively but also emotionally challenging (Haggis, 2006; Gourlay, 2009). An overpreoccupation with learning approaches can result in students being 'pathologised' if they fall short of the 'deep' ideal, an unhelpful deficit view which is often linked to widening participation (Haggis, 2006, p.98). Further assumptions that literacy problems relate only to 'surface features, grammar and spelling' (Lea and Street, 1998, p.159) mean that university teachers often do not see it as their job to teach students to read and write (Haggis, 2006; Wingate, 2015). A deficit perspective also distracts teachers from reflecting critically on aspects of their teaching that might be causing or failing to address the problems (Larrivee, 2000).

A more contextualised way of viewing engagement is to consider its opposite, namely alienation (Mann, 2001; Haggis, 2006; Bryson and Hand, 2007). Among the potential sources of alienation facing students, Mann includes 'the post-modern condition' (2001, pp.8-9, drawing on Lyotard, 1984), whereby a student's motivation is driven by utilitarian goals, such as future employment. If students have extrinsic rather than intrinsic motivations, this is 'perfectly legitimate' according to Haggis (2006, p.527). Moreover, SDT 
proposes that the effect of extrinsic factors on motivation is not necessarily a bad thing, however, its effects can be positive or detrimental, depending on how well behaviours, values and norms associated with extrinsic motivations are internalised (Ryan and Deci, 2000). Accordingly, the more a person experiences externally regulated behaviours as controlling, the less likely they are to act autonomously but rather out of compliance, responding only to external rewards and punishments. By contrast, the more they internalise extrinsic motivations, the more likely they are to accept those behaviours and see them as congruent with their own beliefs and motivation. However, such internalisation requires satisfaction of all three psychological needs for feelings of competence, autonomy and relatedness. Learning facilitative teaching supports development of competence and also relatedness, because teachers with this orientation '...take a personal interest in their students...' (Gow and Kember, 1993, p.28). SDT suggests that if teachers also offer choices, respecting students' freedom to learn as they like (Macfarlane, 2017), they will have stronger feelings of autonomy. By contrast, with its focus on subject content rather than the learner, the knowledge transmission orientation satisfies none of these psychological needs.

Mann (2001, pp.11-12) also suggests that the culture in higher education, with its unfamiliar assumptions, values and practices, can make a student feel like 'an outsider', an issue sometimes assumed to be especially relevant for BME students. However, higher education's culture is new for all students, who find themselves in 'an unknown social grouping of fellow students', which can make for tensions and further challenges (Ylijoki 2000, cited Bryson and Hand, 2007, p.353). These conditions can make students unwilling to express personally held convictions, especially if asked to do this in whole group settings (Millis, 2010) and if their views are at odds with those expressed by others (Mann, 2005; Doyle, 2008). And yet being critical in this way is just what higher education aims to develop (Barnett, 1997), so creating conditions of psychological safety and collegiality in the classroom is crucially important (Mann, 2001), and these are more achievable through small-group activities.

Achieving similar conditions is also the goal of theory concerning cohesion, in settings characterised by diversity, where participants share in creating new culture together (Rathje, 2007). This is radically different to practice where a dominant partner seeks to impose coherence and uniformity in line with their own cultural values. Developing new culture requires dialogue permitting familiarisation so that the different parties can interact 
effectively and, moreover, so that the culture, experience and frames of reference of students from diverse backgrounds can be validated and affirmed, rather than ignored (Howard, 2003; Yosso, 2005).

Once again, the knowledge transmission orientation falls short, since such familiarisation and dialogue are less likely when the teacher does most of the talking, but more so with learning facilitative teaching, which is 'likely to involve interactive class sessions' (Gow and Kember, 1993, p.28).

\subsection{Suggested responses and teaching methods}

Responses meeting the needs highlighted by the above literature include practices advocated in discourse on retention, engagement and transition. This emphasizes the need to develop students' sense of belonging and community, and for this to be supported in the classroom (e.g. Tinto, 2003). Responding to the problems of alienation, Mann (2001, p.18) emphasises criticality and how this can be developed 'through the responses of solidarity, hospitality, safety and the redistribution of power'. In later work, her emphasis shifts to communication aimed at developing mutual understanding and non-judgmental reciprocity, as advocated in the African practice of 'ubuntu' (Tutu 1999, cited Mann, 2005); such an approach is also likely to develop the familiarity needed for cohesion (Rathje, 2007). Haggis's (2006) 'collective inquiry' approach assists realisation of these goals and makes students' disciplinary thinking, reading and writing a key focus.

These goals and practices all emphasise learner-centred, active, and interactive learning principles (e.g. Doyle, 2008; Weimer, 2013). Race's (2009) online introduction to higher education teaching addresses many of the above theoretical perspectives and provides helpful guidance on how they can be applied in practice. Further, practical applications include interdependent, co-operative forms of learning, such as Aronson's jigsaw classroom model (Aronson and Bridgeman, 1979. See also Appendix 1 for a fuller description, and Millis, 2010). Allan's 'Portsmouth Model' of enquiry-based learning supports development of students' critical thinking, speaking, reading and writing skills, at the same time facilitating autonomous and interactive learning (Allan and Powell, 2007. For more on this, see Appendix 2). 'Student-Centred Active Learning Environment with Upside-down Pedagogies' (SCALE-UP), developed by Robert Beichner for large enrolment undergraduate programmes and now rolled out at Nottingham Trent University, 
employs similar principles with additional, technology-enriched support, so that lecture content is mainly accessed online in students' own time, and instead of listening passively in lectures, they work in small groups solving problems, teaching each other and giving feedback (McNeil et al., 2018).

Responses enabling students to integrate new material with existing knowledge (Ausubel, 1963; Biggs, 1996) include concept mapping, as developed by Novak (Novak and Cañas, 2008 - see Appendix 3). Adapting and combining these methods is potentially also fruitful. Appendix 4 evaluates experience combining two of these approaches in the study, and provides material for a staff development activity modelling jigsaw classroom teaching combined with concept mapping, which can be further adapted for more independent, enquiry based learning.

The above literature identifies challenges concerning academic literacy development in a potentially alienating environment, and identifies problems with over-reliance on knowledge transmission teaching methods. In principle, HSS teaching practices appear to provide a suitable mix of approaches, typically comprising:

...the stimulation of a good lecture on the subject, ... engagement with, and exchange of, ideas, expressed verbally in seminars, in response to reading, and... processes of reading and thought involved in the creation of an academic essay. (Haggis, 2006, p.524)

Teaching observed in the department conformed almost exactly to these practices, so what was causing the students' reading and writing difficulties? Before trying to answer this question, methods used in the small-scale study and their limitations are described.

\section{Methods and limitations}

\subsection{Methods}

In order to achieve its aims, this study sought to answer the following research questions:

1. What are the difficulties inherent in students' disciplinary reading and writing?

2. What is done to support development of students' reading and writing? 
3. How could this support be improved?

Approval was sought from the university's Research Ethics Committee, who concluded that the work was 'extremely low risk' and did 'not present any ethical concerns'.

The study gathered a mix of naturally occurring data, from four weeks of teaching observations, and generated data from hour-long interviews with three academics, and hour-long discussions with two student groups comprising four and two first year students respectively. Two academics were chosen because they were module leaders of two core first year modules, designed to introduce and develop theoretical knowledge and skills related to different study goals. The third academic, who had experience teaching one of the modules, was also the department's academic misconduct officer. All first year students on the programme for $2016 / 17$ were invited to participate in focus groups. Despite an incentive, only six volunteered, hence the decision to run two discussion groups on the two days when volunteers were available.

All interviews and discussion groups were recorded and conducted by myself between May and July 2017. In January 2018, I interviewed a further student from the same cohort of students. Teaching observation data had suggested issues related to the psychological needs identified in SDT, so this later interview sought to explore the student's feelings as regards support for competence, autonomy and relatedness.

In weeks 1-4 of the first semester, in October 2017, observations of teaching were conducted by a team comprising three learning developers, including myself, and one educational developer. Two sets of open, non-leading questions were prepared. For the student discussion groups, questions concerned: whether studying their subject was as they expected; what happened in lectures and seminars; how they prepared for lectures and seminars; how they found the reading; how they found the writing; and what guidance they received for writing essays. For the academics, questions concerned: what knowledge students (typically) arrive with; what knowledge they want students to engage in developing; how they would characterise very good quality work; what happens in lectures and in seminars to get students producing work of this quality; and what they think is causing the difficulties. Further questions were allowed to arise spontaneously with the aim of seeking clarification, examples or to test the strength of views held. 
Observation notes and transcripts of the generated data, which amounted to approximately 25,000 words, were read several times and organised under themes suggested by the data. Although an inductive, exploratory approach was initially used, as themes emerged these were compared with existing theoretical perspectives. Understanding thus emerged via an iterative process 'relating findings to a more theoretical framework' (Ritchie et al., 2003, p.253).

\subsection{Limitations}

The methods used in this study involved processes of construction shaped by my prior experience and pre-existing awareness of various theoretical perspectives. Themes for analysis were also reduced by my aim to focus on issues within the control of teachers to address.

The research was also limited, both in terms of the numbers of people interviewed (three academics and seven students) and temporally, with only four weeks of teaching observations. Also, because of my background as a teacher and educational developer, my main focus was on the classroom and lecture experience and this meant that an analysis of text, such as students' coursework or exam essays, was not undertaken.

Because of these limitations, findings are presented as illustrative and hopefully illuminating rather than as robust and replicable. Some findings may have relevance for the BME attainment gap but this was beyond the scope of this study (for examples of relevant perspectives see Howard, 2003; and Yosso, 2005).

\section{Findings}

Teaching on each of the two observed core modules comprised one lecture and one seminar, each of 50-55 minutes. The lectures, recorded and made available on the virtual learning environment, introduced core concepts and theories. The team of observers agreed that the lectures were excellent models of carefully structured, synthesised expert knowledge, which the observed lecturers put across interestingly and with considerable enthusiasm. Lectures were transmitted with few interactions, either lecturer-student or student-student, though some lecturers would occasionally ask a question. Interaction was 
intended to occur in the seminars, but there were considerable differences in levels of participation and these appeared to be aligned with the two teaching orientations identified by Gow and Kember (1993).

\subsection{Challenges for students' reading and writing}

Students in the department have to grasp and work with some difficult ideas and processes. A sense of their complexity was given by one of the academics who described two key concepts, and related practices, as intended to help students understand 'epistemological, ontological positions' and introduce them to 'schools of thought within the discipline ...' and different study goals, '... whether it's to contextually understand or to analyse and test hypotheses'.

Engaging meaningfully with these concepts and practices requires significant shifts in thinking. According to another academic, it ideally involves students 'changing themselves by their reading', taking on board multiple perspectives and 'increasingly making them their own, whether they agree with them or not'; but many students find it 'extremely anxiety inducing' having to handle multiple perspectives and produce work for which 'there is no right or wrong answer', and discovering that '...interpreting the world is a messy, difficult, contested thing'.

The academics described many other challenges which, from their tone of voice, verbal, and body language, often made them sound like student deficits, including the following:

- moving from reading texts to planning and executing a written argument;

- presenting knowledge as argument rather than as information;

- integrating reading effectively and appropriately in their writing;

- openness to new perspectives;

- being critical using other than adversarial, 'pros and cons' type approaches;

- supporting an argument with suitable evidence, and linking such evidence explicitly with the argument; and

- producing coherent syntheses drawn from different perspectives. 
One academic acknowledged the challenges of students' learning needs, admitting that 'it wasn't until my third year [as an undergraduate] that I really thought I understood what our tutors wanted us to do... some of my peers at the time were still not getting it'.

\subsection{Engagement and alienation}

Academics commented on problems with students' motivation and engagement, linking these to external factors, such as 'spoonfeeding' at school, the internet prioritising information rather than thinking, massification of higher education, and an interest only in 'getting a job'. They talked of 'instrumentalism', a lack of intrinsic interest in the Humanities and in developing themselves, and a 'misguided utilitarianism', all of which disinclined students towards committed study and participation, especially in seminars, where 'there's always a question mark as to whether they've done any preparation'.

Lack of participation was especially noticeable where interactions were facilitated by the teacher asking questions to the whole group. In one such session, I noted three students out of about 20 who contributed more than twice, two who responded once, while the remaining 15 remained silent throughout. When no more student contributions were forthcoming, the teacher delivered a mini-lecture on points not yet covered. According to one of the students, this format was typical:

...if people don't want to discuss... the reading during the seminar, ... we basically spend the whole seminar, we - well, our teacher - talks for an hour straight because no-one wants to discuss it.

The lack of participation in seminars was criticised by two of the academics and by students who expressed frustration that, while they prepared for seminars and made efforts to contribute, others sat in silence or would be 'on their laptops, scrolling through Facebook'. However, commentary by another student suggested that the teaching was at fault:

I didn't have a good experience with one of my seminars... The teacher was... just talking to two people during the whole first semester... [A] lot of people said they didn't enjoy it because they didn't take part in the discussions at all. 
This lack of interaction also appeared to affect relationships within seminar groups. One student said that while some tutors made an effort to connect and that 'this made a real difference', this was more the exception than the rule:

They didn't make a personal connection... In the seminar you're a student - a person - but after that you're just like someone they might pass in the street. And it's the same with other students. You pass the same staff or the same student you were with, in the seminar, and they don't acknowledge you.

Observations of tutors in the classroom make this comment surprising. However, a lack of group cohesion and limited connection between individual students were certainly apparent in these sessions: little or no banter as they arrived or were leaving; little acknowledgement of the tutor; eyes mainly down throughout the session.

Academics generally attributed the lack of interaction to poor preparation and engagement. One believed that students needed to approach their studies as they would 'a marathon', maintaining consistent effort over a prolonged period, however most students put in only a series of short 'sprints' coinciding with assessment submission deadlines. The same academic did not agree that the right response was to do more for students:

'More support' - that's always the answer: 'more support; more help; more structure; it's more resources', and I think you end up chasing down a rabbit hole. The more support and resources you give, the more likely they are to demand it.

Such additional support would be wrong, they argued, because it would discourage autonomy:

What you're trying to inculcate in young people is independence. What I want for students is to be independent of me, independent of adults, adult authority. It's about becoming an autonomous human being. That's for me what university education is about.

To achieve this autonomy, the rules of academic engagement needed to be made explicit: 
...they've got to realise that in order to be at university and to flourish and to succeed, they've got to work hard - they have to apply self-discipline. And... they've got to be inculcated into our discipline, and our norms and expectations, ... so we need to make it as explicit as possible... it is about socialising them to the rules, habits, values of our institution'.

Despite doing much to make these norms explicit, academics reported that many students failed to take them on board, for example: 'What I teach them doesn't show up in their work'.

Not all seminar teaching followed the same pattern. The following description highlights students being supported to learn actively:

We start with things like, ... 'Here's some different views on [the subject discipline], completely different views. Set them in argument with each other and try to decide who's right and wrong [and] how you can read an article critically and analytically'. So they do some exercises in class, then they write on that... Then we look at the way [theories are] applied in case studies and ask them to use those theories in a research essay. It's very, very scaffolded, ... the next piece builds on the rest and they do exercises in workshop format and seminars, and then go away and do this stuff.

Scaffolded activities were also evident in some observed seminars. In one, the tutor structured activities so that students could work collaboratively, reading, discussing and writing on subject disciplinary concepts and arguments. Prepared grids helped students analyse textual material by grouping concepts under key-word headings prior to writing short paragraphs. With students working in groups, the tutor could move between them providing feedback or prompting them to think further via questions.

Apart from their deliberate focus on disciplinary literacy development, these sessions were also noteworthy for high levels of participation. In the above example, every student participated actively.

Student commentary provides further evidence of such learning facilitative practice and also of their appreciation of it; however, they did not feel there was enough of it: 
We had some exercises on how to write a paragraph, using the reading that we've done, and that was very helpful... I was a bit confused what it all meant but I wrote a paragraph, shortly summarising the reading and that was very helpful. Then we read it out loud in front of the whole class... My understanding was a bit... shallow I would say, but then when I heard the other people's paragraphs I could maybe understand more what [the author] meant. [W]riting these paragraphs... helped me... [understand] how to use readings in writing. I wish we'd done it more often, like every other week, 'cause we only did it three times in the year.

Another student, who said they only had one such seminar, emphasised the value of such development:

It would have been helpful... [to learn] how to include the reading... when you write, because that's what I struggled with.

\section{Discussion of the findings}

The findings appeared to reflect the above literature, which emphasised the challenging nature of undergraduates' reading and writing development: its complexities; students having to get to grips with these, often with insufficient support, in an alien environment; the need for familiarisation with both discourse practices and people; and potential motivation issues if psychological needs are not met. Where learning activities were structured and designed to support this development, students participated and were appreciative but felt they were not getting enough practice. In contrast, where teachers did much of the talking and did not provide structure or scaffolding for activities such as discussion, students generally did not participate, did not appreciate the experience and did not appear to connect with the teacher or with each other. From an SDT perspective, the strong orientation towards knowledge transmission - not only in lectures but also in seminars - can thus be interpreted as failing to develop students' feelings of competence and relatedness, making it less likely that they will engage in autonomous, self-directed learning (Niemiec and Ryan, 2009). It also does not foster the familiarity needed for cohesion (Rathje, 2007) in the potentially alien higher education environment (Mann, 2001). 
This interpretation suggests that engagement issues must not simply be seen in terms of student deficits, or of factors which are outside teachers' control, but rather as matters which teachers can and need to address. An example of this was the generally low level of participation in seminars, often interpreted as reflecting poor engagement. This overlooks the fact that the method often used to facilitate interactions - asking questions to the whole group - is highly likely to result in most students remaining silent (Doyle, 2008; Millis, 2010). It is therefore possible to view non-participation as 'a lack of skill on the part of the teacher' which '....needs to be understood as a teacher deficit, not a student deficit' (Macfarlane, 2017, p.110). Non-participation is problematic from a constructivist perspective because it is through putting ideas into their own words that students learn to articulate new material and integrate it with prior knowledge (e.g. Ausubel, 1963; Biggs, 1996). It also contributes to feelings of alienation. In end-of-first-year interviews for another recent project, several students from different departments and faculties emphasised the unwelcoming atmosphere they experienced in the classroom, one commenting that the lack of interaction in seven out of eight modules had been their biggest disappointment during their first year at university.

\section{Tentative conclusions}

Just as students need to learn critical thinking and self-reflection so as to scrutinise and justify decisions, beliefs and actions (Barnett, 1997), higher education teachers also need to consider critically their own assumptions about teaching and the practices they employ to bring about learning, which are often unexamined and unchallenged, so that they can remain unaware of their implications for students' learning (Mezirow, 1990; Larrivee, 2000). Regarding literacy development, key assumptions concern the challenges inherent in students' reading and writing (Lea and Street, 1998; Meyer and Land, 2003; Haggis, 2003; Gourlay, 2009); issues concerning engagement and assumed student deficits (Haggis, 2003; 2006), and the alienating practices and environment of higher education (Mann, 2001; Haggis, 2006; Bryson and Hand, 2007).

Some teaching practices in higher education focus on meeting students' learning needs, however, with other practices the goal of teaching is to transmit content, regardless of whether it brings about the intended learning and enables students to work with that content. These two teaching strategies, oriented towards learning facilitation or knowledge 
transmission, and their links to more or less desirable learning approaches and outcomes, have long been recognised (Gow and Kember, 1993; Kember, 1997), and yet over-reliance on knowledge transmission in many university departments often leaves students illequipped and poorly motivated to engage autonomously with their learning (Niemiec and Ryan, 2009).

Academics are under intense pressures arising from their dual roles related to research and teaching, and to increased cohort sizes. This can make it difficult to engage adequately with the theoretical perspectives and practices needed in their work as teachers and which, incidentally, can make their teaching a lot more enjoyable. Those responsible for the provision of teaching must recognise that 'students are more likely to persist and graduate in settings that provide academic, social, and personal support (Tinto, 2003, p.3). This requires adequate staffing levels, with sufficient time on staff workloads, so that teaching is given the priority it needs. It also requires suitable professional development, so that teachers understand these issues and are able to achieve the conditions needed for students to thrive.

\section{Implications for future research}

The findings provide evidence that there are higher education teachers who are engaging well with many of the ideas, issues and practices discussed in this article, and applying them in their teaching. However, not all are and the reasons for this, and how to encourage and support such engagement, would be worth investigating.

The implications of SDT have been researched in primary education reading development (e.g. De Naeghel et al., 2014), in physical education (Ntoumanis, 2001), and in education more generally (Niemiec and Ryan, 2009), but its relevance for reading and writing in higher education is under-researched. A more in-depth study would therefore be worthwhile.

The implications of SDT for engagement and alienation in higher education also appear from the findings to be suitable areas for research, as would be a specific focus on efforts to understand the BME attainment gap. 


\section{References}

Allan, G. and Powell, N. (2007) 'Examining the underlying principles of enquiry-based learning: two instances of where learning sessions start and end', The International Journal of Learning,14(8), pp. 157-165.

Aronson, E. and Bridgeman, D. (1979) 'Jigsaw groups and the desegregated classroom: in pursuit of common goals', Personality and Social Psychology Bulletin, 5(4), pp. 438446.

Ausubel, D.P. (1963) The psychology of meaningful verbal learning. New York: Grune and Stratton.

Barnett, R. (1997) Higher education: a critical business. Oxford: Oxford University Press.

Biggs, J. (1996) 'Enhancing teaching through constructive alignment', Higher Education, 32(3), pp. 347-364.

Biggs, J. and Tang, C. (2011) Teaching for quality learning at university. $4^{\text {th }}$ edn. Maidenhead: Open University Press / McGraw-Hill Education.

Bryson, C. and Hand, L. (2007) 'The role of engagement in inspiring teaching and learning', Innovations in Education and Teaching International, 44(4), pp. 349-362.

De Naeghel, J., Van Keer, H. and Vanderlinde, R. (2014) 'Strategies for promoting autonomous reading motivation: a multiple case study research in primary education', Frontline Learning Research, 3(2014), pp. 83-101.

Doyle, T. (2008) Helping students learn in a learner-centered environment. A guide to facilitating learning in higher education. Sterling, Virginia: Stylus Publishing, LLC.

Gourlay, L. (2009) 'Threshold practices: becoming a student through academic literacies', London Review of Education 7(2), pp. 181-192. 
Gow, L. and Kember, D. (1993) 'Conceptions of teaching and their relationship to student learning', British Journal of Educational Psychology. 63(1), pp. 20-33.

Haggis, T. (2003) 'Constructing images of ourselves? A critical investigation into 'Approaches to Learning' research in higher education', British Educational Research Journal, 29(1), pp. 89-104.

Haggis, T. (2006) 'Pedagogies for diversity: retaining critical challenge amidst fears of 'dumbing down”, Studies in Higher Education, 31(5), pp. 521-523.

Hay, D., Kinchin, I. and Lygo-Baker, S. (2008) 'Making learning visible: the role of concept mapping in higher education', Studies in Higher Education, 33(3), pp. 295-311.

Howard, T.C. (2003) 'Culturally relevant pedagogy: ingredients for critical teacher reflection', Theory into Practice, 42(3), pp. 195-202.

Kandiko, C., Hay, D. and Weller, S. (2012) 'Concept mapping in the humanities to facilitate reflection: externalizing the relationship between public and personal learning', Arts and Humanities in Higher Education, 12(1), pp. 70-87.

Kember, D. (1997) 'A reconceptualization of the research into university academics' conceptions of teaching', Learning und Instruction, 7(3), pp. 255-275.

Larrivee, B. (2000) 'Transforming teaching practice: becoming the critically reflective teacher', Reflective Practice, 1(3), pp. 293-307.

Lea, M. and Street, B. (1998) 'Student writing in higher education: an academic literacies approach', Studies in Higher Education, 11(3), pp. 182-99.

Macfarlane, B. (2017) Freedom to learn. The threat to student academic freedom and why it needs to be reclaimed. London: Routledge, Taylor and Francis.

Mann, S. (2001) 'Alternative perspectives on student learning: alienation and engagement', Studies in Higher Education, 26(1), pp. 7-19. 
Mann, S. (2005) 'Alienation in the learning environment: a failure of community?', Studies in Higher Education, 30(1), pp. 43-55.

Marton, F. and Säljö, R. (1976) 'On qualitative differences in learning: I - outcome and process', British Journal of Educational Psychology, 46(1), pp. 4-11.

McNeil, J., Borg, M., Kennedy, E., Cui, V., Puntha, H. and Rashid, Z. (2018) SCALE-UP Handbook. Nottingham: Nottingham Trent University [Online]. Available at: https://www4.ntu.ac.uk/adq/document uploads/teaching/181133.pdf. (Accessed: 25 September 2018).

Meyer, J.H.F. and Land, R. (2003) 'Threshold concepts and troublesome knowledge: linkages to ways of thinking and practising within the disciplines', in Rust, C. (ed.) Improving student learning: improving student learning theory and practice - ten years on. Oxford: Oxford Centre for Staff and Learning Development, pp. 1-16.

Meyer, J. and Land. R (2005) 'Threshold concepts and troublesome knowledge (2). Epistemological considerations and a conceptual framework for teaching and learning', Higher Education, May issue, pp. 373-388.

Mezirow, J. (1990) 'How critical reflection triggers transformative learning', in Mezirow, J. and Associates (eds.) Fostering critical reflection in adulthood. San Francisco: Jossey Bass, pp. 1-20.

Millis, B.J. (2010) Cooperative learning in higher education. Across the disciplines. Across the academy. Sterling, Virginia: Stylus Publishing, LLC.

Niemiec, C. and Ryan, R. (2009) 'Autonomy, competence, and relatedness in the classroom. Applying SDT to educational practice', Theory and Research in Education, 7(2), pp. 133-144. 
Novak, J.D. and Caňas, A.J. (2008) The theory underlying concept maps and how to construct and use them. Technical Report IHMC CmapTools 2006-01, Rev 012008, pp. 1-36. Available at:

http://cmap.ihmc.us/Publications/ResearchPapers/TheoryUnderlyingConceptMaps. pdf. (Accessed: 30 January 2018).

Ntoumanis, N. (2001) 'A self-determination approach to the understanding of motivation in physical education', British Journal of Educational Psychology, 71, pp. 225-242.

Prosser, M. and Trigwell, K. (1999) Understanding learning and teaching. Buckingham: SRHE and Open University Press.

Race, P. (2009) In at the deep end. Starting to teach in higher education. $2^{\text {nd }}$ edn. Leeds Met Press [Online]. Available at:

https://phil-race.co.uk/wp-content/uploads/downloads/2013/05/In-at-the-DeepEnd.pdf. (Accessed: 26 June 2018).

Ramsden, P. (1992) Learning to teach in higher education. London: Routledge.

Rathje, S. (2007) 'Intercultural competence: the status and future of a controversial concept', Language and Intercultural Communication, 7(4), pp. 254-266.

Ritchie, J., Spencer, L. and O'Connor, W. (2003) 'Carrying out qualitative analysis', in Ritchie, J. and Lewis, J. (eds.) (2003) Qualitative research practice. A guide for social science students and researchers. London: Sage Publications Ltd, pp. 219262.

Ryan, R., and Deci, E. (2000) 'SDT and the facilitation of intrinsic motivation, social development, and well-being', American Psychologist, 55(1), pp. 68-78. 
Tinto, V. (2003) 'Promoting student retention through classroom practice', Presented at Enhancing Student Retention: Using International Policy and Practice. Amsterdam 5-7 November [Online]. Available at:

http://gaia.flemingc.on.ca/ imior/EDu705Humber/Articles/Tinto\%20Retention.pdf. (Accessed: 7 October 2018).

Weimer, M. (2013) Learner-centered teaching. Five key changes to practice. $2^{\text {nd }}$ edn. San Francisco: Jossey-Bass.

Wilkinson, J. and Olason, C. (2012) 'Supporting work and inquiry via a CLEAR approach: combined learning for employability and research', VISTAS: Education, Economy and Community. The University of West London Journal, 1(3), pp. 29-48.

Wingate, U. (2015) Academic literacy and student diversity. The case for inclusive practice. Bristol: Multilingual Matters.

Yosso, T. (2005) 'Whose culture has capital? A critical race theory discussion of community cultural wealth', Race Ethnicity and Education, 8(1), pp. 69-91.

\section{Author details}

James Wilkinson has taught in higher education for more than 25 years in both teaching focused and research intensive institutions, and was awarded a National Teaching Fellowship in 2010. He currently works in educational development at one London-based Russell Group university and in learning development at another similar institution.

\section{Appendix 1. The Jigsaw Classroom}

The jigsaw classroom approach was developed by Elliott Aronson in the 1970s as a response to major problems, including physical violence, and poor associated learning outcomes (Aronson and Bridgeman, 1979) following de-segregation in American schools. This context clearly differs from that of UK higher education today, however there are certain parallels. Just as de-segregation of schools in the United States had brought 
together students previously kept apart, widening participation in British higher education has brought together white, middle class students, for whom university was always an expectation, with students from different ethnic, racial and social backgrounds, who may be the first in their family to go to university. Seminar groups may not have the same competitive or antagonistic dynamic as the 'traditional classrooms' described by Aronson and Bridgeman, but where the teaching is teacher-centred and transmission-based, they are still marked by a tendency for few students to participate actively while many do not.

Aronson and Bridgeman provide evidence that the 'traditional classroom' fosters an environment which fails to develop students' motivation or their ability to interact and work constructively with their peers. By contrast, the Jigsaw Classroom facilitates learning cooperatively in 'Learning Groups' comprising six students working towards common goals:

i. Individual students develop expertise by researching one of six different sub-topics, for which materials are provided;

ii. They share and discuss knowledge in 'Expert Groups' with 5 students from other groups who have been researching the same sub-topic;

iii. Next, they return to their original learning group and teach team members about their topic.

iv. They are individually tested on all six topics.

Aronson and Bridgeman's research identified important benefits. Because they will be individually tested, students are motivated to do a good job of teaching their colleagues, and when being taught, they understand that it is in their interests to listen and be supportive:

....results indicate that... structured interdependence increases the self-esteem, the morale, the interpersonal attraction, and the empathy of students across ethnic and racial divisions, and also improves the academic performance of minority students without hampering the performance of the ethnic majority. (Aronson and Bridgeman, 1979, p.438) 


\section{Appendix 2. Concept mapping}

Using concept mapping as a teaching strategy allows teachers to gauge students' understanding and to provide feedback quickly and easily. Drawing on constructivist conceptions of learning (notably Ausubel,1963), concept maps were developed by Josef Novak in the early 1970 s as a tool to help researchers visualise changes in children's learning of science concepts (Novak and Cañas, 2008). To make apparent the assimilation of new concepts, Novak's concept maps comprise concept labels together with cross-links (words or phrases) which show the relationship between the different concepts. Each pair of concepts and link thus represent a proposition (see example below). Because crosslinks make visible the 'meaningful learning' and related understanding, Hay et al. (2008, p.302) argue that concept mapping:

... is much more stringent than mind mapping... and actively differentiates between knowledge (of appropriate concept labels) and understanding (that is the product of concept linkage).

As is evident from the above focus groups and interviews, subject disciplinary writing is a challenge for many students. It is also time-consuming for teachers to assess and provide formative feedback. Kandiko et al. (2012) propose that concept mapping offers opportunities for students to develop arguments and organise ideas, and facilitates feedback and reflection. Concept mapping can thus be used in conjunction with written assignments to facilitate tutors engaging with students as they are building understanding, and before submitting their written work for assessment.

To illustrate this potential to present and visualise meaningful understanding of ideas, the above propositions are presented in the concept map below (and include ideas from the theoretical framework presented earlier). Starting with 'Concept Maps' (centre top), the map can be 'read' by following the links and arrows to other labels, thus making a series of propositions and complete sentences. For example: 'Concept Maps comprise concept labels plus words/phrases (which) link new knowledge with existing cognitive structure'. 


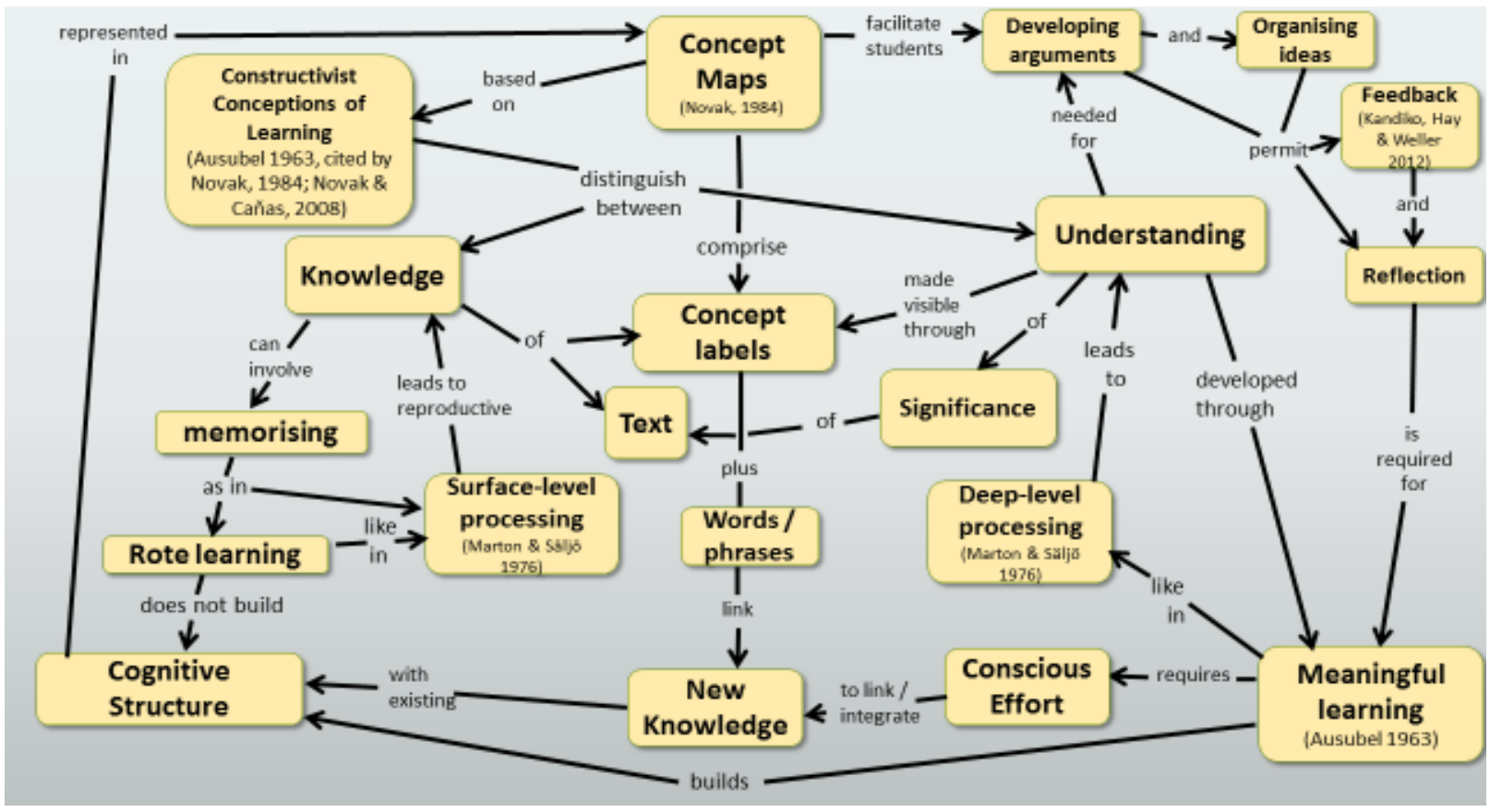

Figure 1. Concept mapping presented in the form of a concept map.

\section{Appendix 3. Enquiry based learning}

The shift in my teaching towards more learning facilitative approaches emerged from critical reflection and by my attending a highly active and interactive workshop facilitated by George Allan. This was designed so that participants would experience - rather than be told about - his 'Portsmouth Model' of enquiry based learning (EBL) (Allan and Powell, 2007). Participants did most of the work while he did relatively little during the actual workshop, appearing relaxed, keeping us busy and gently challenging us with questions. To summarise Allan's approach, the following vignette describes my experience of the workshop and includes key features of the approach:

George did not talk at me and my 25 or more fellow participants (university lecturers) other than briefly at the start and at the end of the workshop. Instead, he had us all working hard, not only during the workshop but also before it had even started, when he asked us each to bring notes on a paper we had found on a topic relevant to the workshop's theme. He also explained why this would be useful. In the workshop, later, he explained the importance of motivating students by telling them how the next learning topic will be relevant and valuable for them, relating it to their interests and needs. However, this was not until we had worked in groups of 
four, discussing and critiquing each other's papers and producing a (hopefully) nuanced and coherent written synthesis of the main ideas from all four papers. We then moved around the room, reading the work produced by other groups. It was hard work and also an eye-opener. For one thing, it reminded us how challenging the kind of work we ask our students to do is, and how much it involves. For another, it showed us how important it is to get students doing the things we want them to learn.

\section{Appendix 4. Trialling, evaluating, and refining combined approaches.}

Two teaching practices - jigsaw classroom and concept mapping - were combined and trialled on the programme, in every seminar group of one module during Week 4 of the first semester in 2017/18. Students worked in small groups of three students, each taking responsibility for reading a paragraph of text - an extract from a book chapter that students were asked to read in advance - and explaining the paragraph's main ideas to the other two group members. When each student had explained the ideas from their paragraph, each group then designed and presented a concept map representing the ideas from all three paragraphs. They were also shown an example of a concept map on which the concept labels and cross-linking phrases were pointed out.

In the event, this was a mixed experience. With the exception of one seminar group, students participated actively and appeared to find the activities motivating. The module convenor commented that it had introduced useful collaborative and individual skills for reading, discussing and structuring ideas from texts. However, concept mapping was timeconsuming, and not all groups remembered to include the important cross-links. Further problems were observed in one, unusually small seminar group, where there were only enough students to form two groups of three students. The seminar tutor, a post-doc Teaching Assistant with limited teaching experience, had missed a training session introducing the combined approaches with their emphases on active and interactive learning. Instructions were given to the students rather hastily and, because the students stopped engaging with the activity after about 20 minutes, the tutor delivered a mini-lecture and did not attempt to motivate students to continue with the activity. 
This experience emphasises the need for suitable development opportunities before attempting such activities, so that higher education teachers are aware of underpinning theoretical perspectives and can be shown ways of applying these in practice.

Remarkably, during a recent staff development event, I provided too much text and not enough time for participants to digest and discuss it, thus doing the very thing that this article should have warned me not to do.

Changes made in the light of this experience have included shortening the texts to a few lines only and getting students to complete partially completed concept maps. The activities can be designed to introduce such an activity to teaching staff. Working in groups of six, each participant is given one text only, reads it and explains it to their colleagues in their own words. The group discusses all six texts, comparing them with their own experience and considering them critically. They then fill the gaps on the partially completed concept map together, then use this to assist them in producing written syntheses of the ideas from all six texts, expressing them in their own words and including references. The material below could be used to provide scaffolding for these activities.

The following are extracts (slightly adapted) from: Wilkinson, J. (2018) Engagement in higher education. Who's not engaging? Journal of Learning Development in Higher Education (in press).

A.

A challenge for higher education teaching is to build students' capacities for inquiry, reading and writing in the discipline, which allow them to discover, unpack and apply knowledge critically in new contexts, for new purposes (Lea and Street, 1998; Haggis, 2003; Wingate, 2015).

B.

Developing students' academic literacy is challenging because the practices involved, their underpinning epistemological foundations and the sociocultural conditions in which students have to learn them, are likely to be alien for students (Mann, 2001, Haggis, 2006; Bryson and Hand, 2007). 
C.

Achieving cohesion, rather than uniformity and coherence, requires dialogue permitting familiarisation, so that the different parties can interact more effectively and comfortably (Rathje, 2007).

D.

The assumption that teaching means transmitting knowledge was one of the teaching conceptions identified by Gow and Kember (1993). The other one was that teaching is understood to mean bringing about intended learning (learning facilitation).

\section{E.}

The familiarisation needed for cohesion in the classroom is less likely to develop with the knowledge transmission orientation because this involves the teacher doing most of the talking. The learning facilitative teaching, on the other hand, is 'likely to involve interactive class sessions' (Gow and Kember, 1993, p.28).

\section{F.}

[Self-Determination Theory] suggests that learning facilitation - unlike knowledge transmission - fosters students' feelings of competence, autonomy and relatedness, assisting internalisation of externally regulated behaviours, and increasing preparedness for engaged, self-directed learning (Niemiec and Ryan, 2009). 


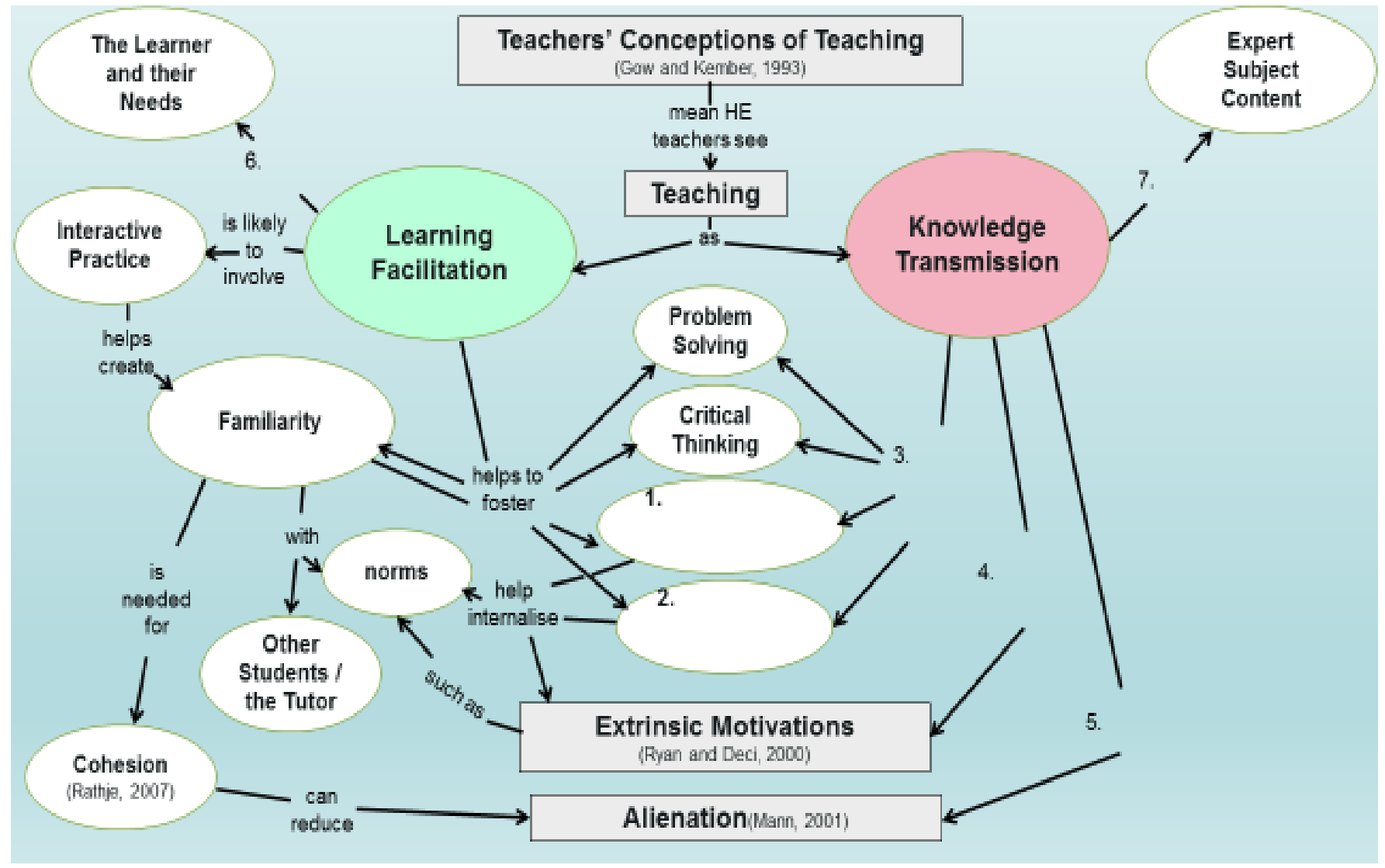

